From the Laboratory of Neuropathology, Neuropsychiatric Institute, University of Michigan Hospital, Ann Arbor, Michigan

\title{
Nervous End-Structures in the Human Neurohypophysis*
}

\author{
A study with silver carbonate
}

By

\author{
Leopold Liss M. D. **
}

With 10 Figures

The understanding of the hypothalamo-hypophysial system, and its importance in the clinical fields, has increased considerably in the last years. Parallel to this development, the histology of the neurohypophysis was investigated by Bucy (1932), Romeis (1940), Buno (1954), Brettschneider (1955) and others.

The neurohypophysis is the place where the neurosecretory substances are brought from the hypothalamic nuclei and from whence the they are released (Scharrer and Scharrer 1954, Bargmann 1954). This highly specialized function requires an intricate nervous receptory and release mechanism. Spatz (1951) in his analysis of the interrelationship between the hypothalamus and hypophysis postulated a humoral and nervous centrifugal and centripetal path. Romeis (1940) has demonstrated that the majority of the nerve fibers from the hypothalamo-hypophysial tract end in the posterior lobe, some in the intermediate and few only in the anterior lobe of the hypophysis. The way in which these fibers end in the posterior lobe was described by Romeis as end-baskets and free endings. Rennels and Drager (1955) introduced evidence of basic importance: neurosecretory nervous terminals around pituicytes. Brettschneider (1956) described specialized nervous endings in the infundibular blood vessels of a horse and designated them as receptors. In our own investigations of the cellular elements in the human neurohypophysis there were findings which indicate a very close relationship between the pituicytes and the nerve fibers from the hypothalamo-hypophysial tract. In the present studies we demonstrated several forms of nerve endings which represent a part of the regulatory mechanism for neurosecretion.

* Dedicated to the memory of Prof. Albert Kuntz, a distinguished scientist and teacher.

** Supported by Grant No. B-1251 of the United States Department of Public Healt, Education and Welfare. 


\section{Material and Methods}

For present studies were used human neurohypophyses obtained on routine post-mortem examinations. The specimens were fixed in bromformalin (Cajal's solution) and frozen sections 15 microns thick were impregnated with the silver carbonate technique of del Rio Hortega.

\section{Description of Material}

The nerve fibers of the hypothalamo-hypophysial tract enter in large numbers the infundibulum of the neurohypophysis and the majority of them reach the posterior lobe; although there are nerve fibers, few in number, which terminate in the uppermost portion of the infundibulum in the wall of the recessus infundibuli. Fig. 1 shows a few coarse nerve fibers which form a thin bundle which then divide, and each fiber ends among the ependymal cells which line the third ventricle. These nerves terminate as: a) free endings; or b) bud-like end-formations. Both types of endings are intimately connected with the ependymal cells.

The connection between the blood vessels and nerve fibers in the posterior lobe of the pituitary is demonstrated in fig. 2. From a bundle of fine nerve fibers (a), one nerve fiber (b) leaves the parallel course and terminates on a capillary wall (c). This nerve ending appears to be a small "sucker foot" which makes distinct connection with the extremely fine perivascular nerve plexus.

The parallel nerve bundles from the infundibulum disperse after they enter the posterior lobe. Some of the nerve fibers assume a parallel arrangement and can be found in the caudal pole of the posterior lobe (fig. 3). The majority of the nerve fibers do not follow a pattern but can be found as single fibers or as small networks between the pituicytes and their processes (fig. 4). This relationship between the nerve fibers and pituicytes is very close and is identical in the infundibulum and in the posterior lobe. Fig. 5 shows a nerve fiber which terminates in a pituicyte (a). This termination, which is from the posterior lobe, has taken the form of a minute basket and is independent from the fine loose nervous network which surrounds all the pituicytes. The same type of ending, but in infundibulum, is shown in fig. 6 .

A somewhat different relationship between the nodular ending in the pituicyte and the loose nervous network is shown in fig. 7. The pituicyte (a) shows a nodular nerve termination similar to these described, but the nerve fiber which terminates there arises from the loose nervous network. There is no nerve ending in the pituicyte at (b), but the nerve fibers form a dense network around it, and some have free endings.

Since the already described types of nerve endings are variations of two essential types, fig. 8 shows the small dense nerve ending of glomerular type. This type of ending is formed by very fine nerve fibers and there is no indication for assuming any relationship between this small, dense endglomerulus and the pituicytes. 
An entirely different type of nervous ending in the neurohypophysis is shown in fig. 9 and 10. This is a large glomerulus formed by intertwined fine nerve fibers. It is much larger than the endings already describedi and
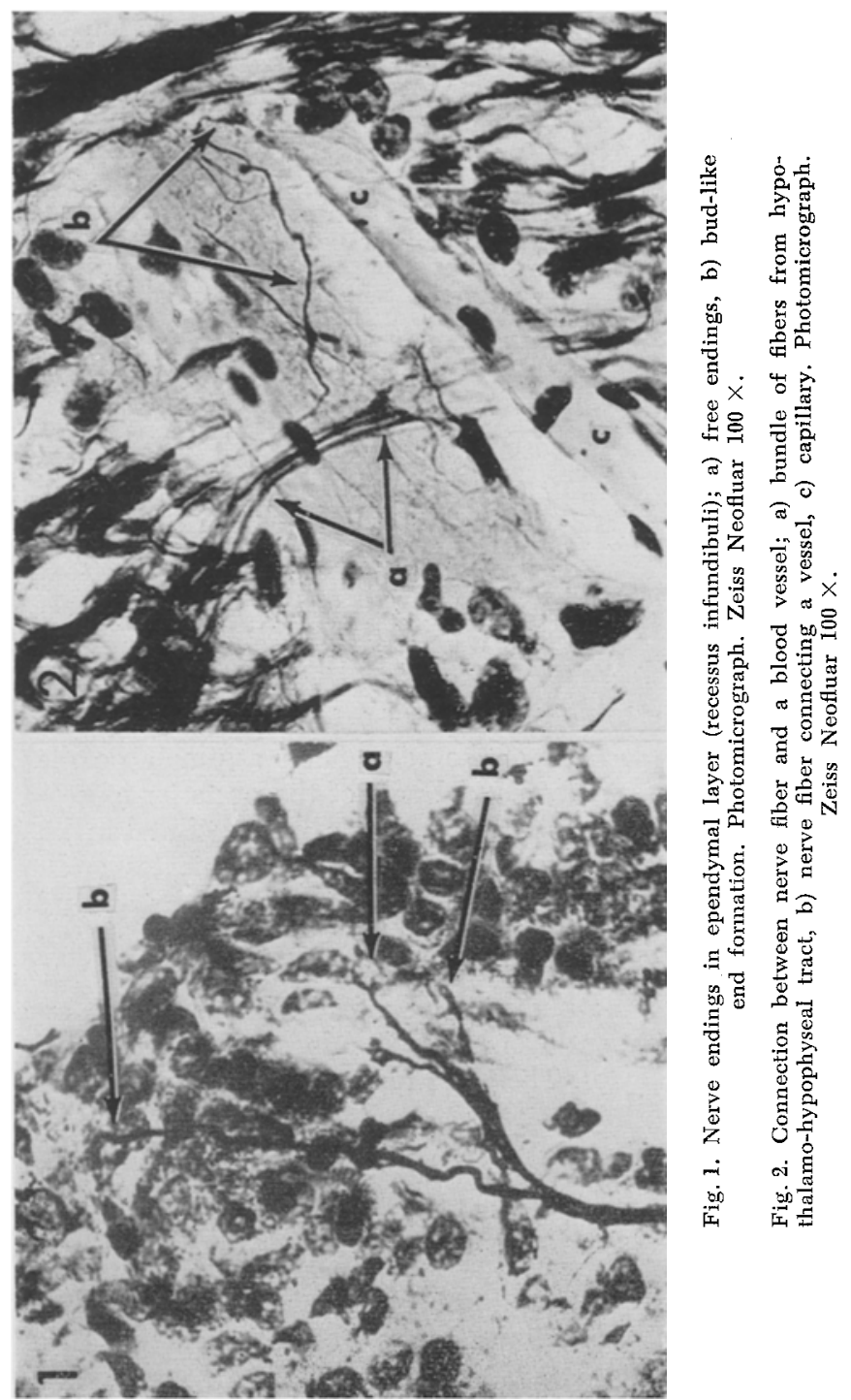

in its structure are included several pituicytes. The nerve fibers from the network terminate on the pituicytes and form fine brush-like end structures (fig. $10 \mathrm{a}$ ). 


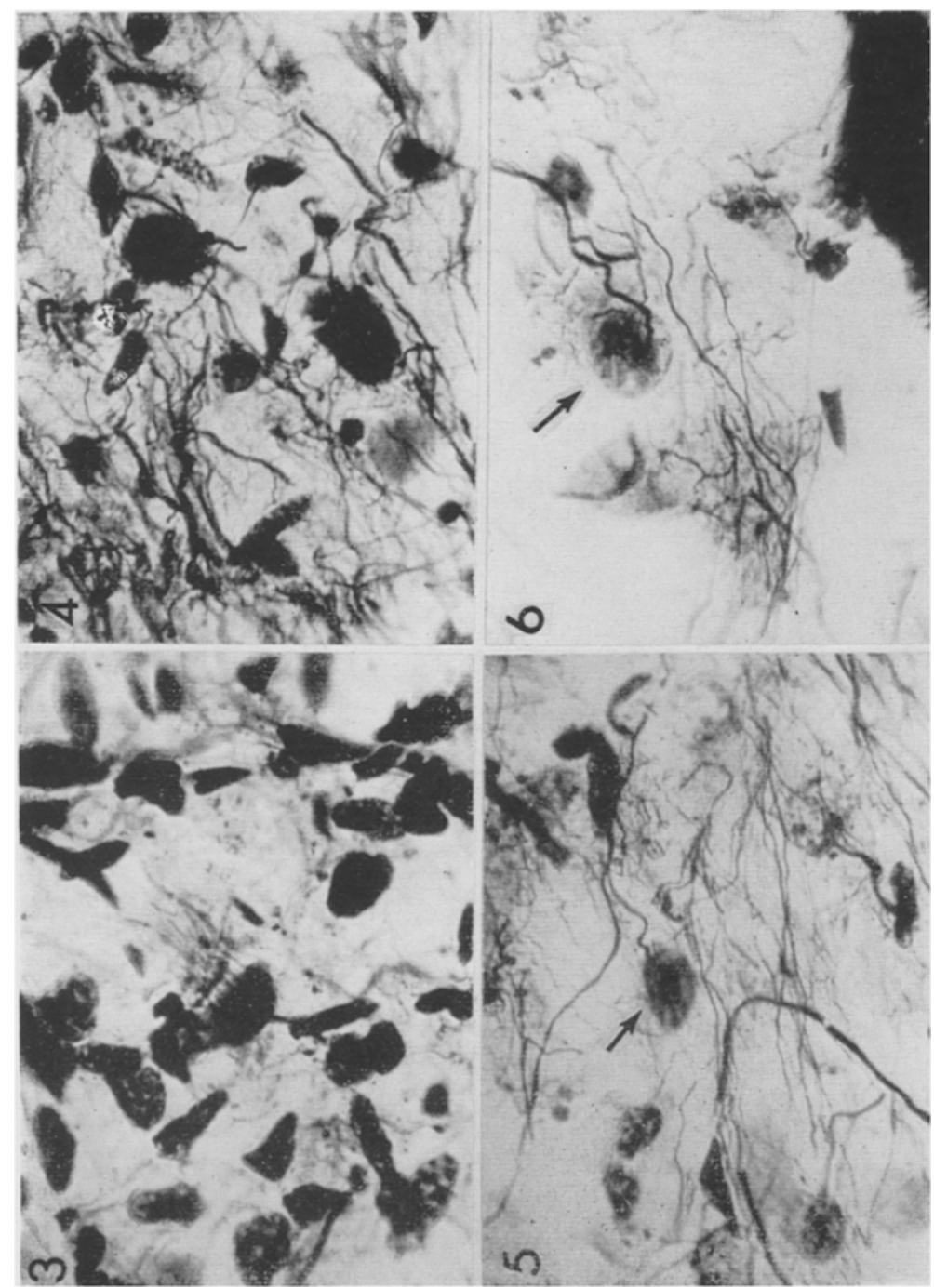

Fig. 3. Pituicytes and nerve fibers in parallel arrangement (caudal pole of the posterior lobe). Photomicrograph. Zeiss Neofluar $100 \times$.

Fig. 4. Pituicytes and fine nervous network in the neurohypophysis. Photomicrograph. Zeiss Neofluar $100 x$

Fig. 5. Bud-like nerve fiber ending in a pituicyte (posterior lobe). Photomicrograph. Zeiss Neofluar $100 \times$.

Fig. 6. Nerve ending in a pituicyte of the same type as figure 5 (infundibulum). Photomicrograph. Zeiss Neofluar $100 x$. 


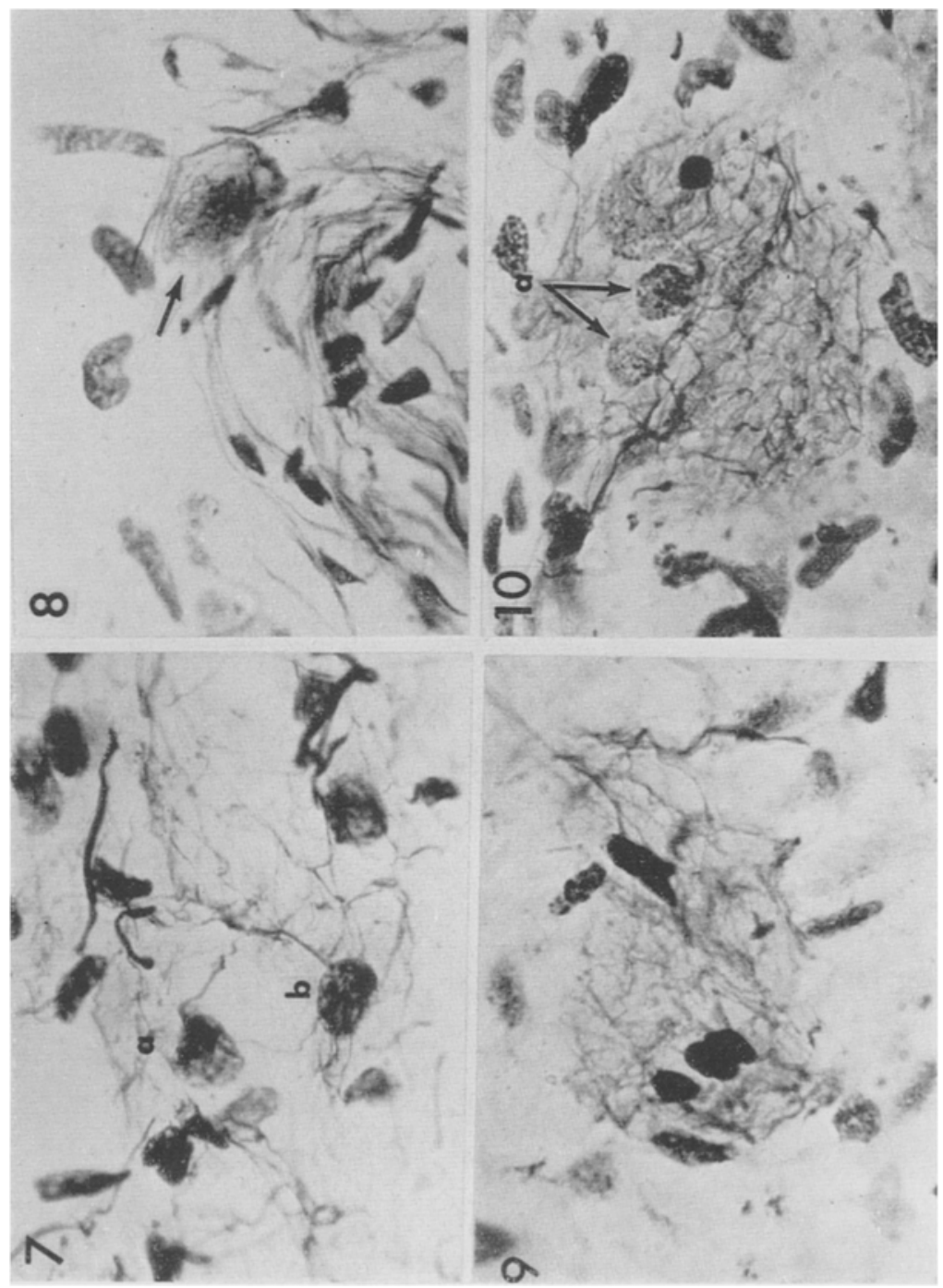

Fig. 7. Loose nervous network in the neurohypophysis; a) pituicyte with nervous ending, b) pituicyte with pericellular nervous network. Photomicrograph. Zeiss Neofluar $100 \mathrm{X}$.

Fig. 8. Dense glomerular nervous end-formation formed by extremely fine nerve fibers without any relation to pituicytes. Photomicrograph. Zeiss Neofluar $100 \times$.

Fig. 9. Nervous ending of the giant glomerular type. Photomicrograph. Zeiss Neofluar $100 \times$.

Fig. 10. Nervous ending of the giant glomerular type. Note the brushlike nervous endings on the pituicytes (a). Photomicrograph. Zeiss Neofluar $100 \times$. 


\section{Comment}

We have demonstrated several types of nerve endings characteristic for the terminations of the nerve fibers from the hypothalamo-hypophysial tract in neurohypophysis. These nerve endings can be arbitrarily divided into two groups: 1) ending of single fiber; 2) ending in a network. Our findings postulate the following subdivisions of nervous terminations:

\section{Ending of a single fiber:}

A. Ending in the ependymal layer:

1. Free ending.

2. Bud-like end formation.

B. Ending on a blood vessel.

C. Ending on pituicytes:

1. Free nerve endings.

2. Bud-like formation with or without connection with the loose network.

3. Brush-like ending from the giant glomerular end formations.

\section{Networks:}

A. Loose network which embeds the entire neurohypophysis.

B. Dense, small glomerular end-formation without any relation to pituicytes.

C. Giant end-glomeruli with close relations to pituicytes.

The different types of nervous terminations were found both in the infundibulum and in the posterior lobe; this findings adds to the proof of functional unity of the neurohypophysis (Spatz, 1951).

The only type of endings which are limited to one location are those among the ependymal cells in the recessus infundibuli. Since Rennels and Drager (1955) described the proximal zone of infundibulum without sighting any evidence of storage of the neurosecretory material, it should be concluded that the nerve fibers which terminate in the ventricular wall are not carrying neurosecretory material, but are centripetal and their function is receptory. It is impossible to determine from histological findings alone what the difference is in function between the free endings and the budlike formations.

The endings on the blood vessel correspond to a certain degree with Brettschneiders (1956) findings, who classified these endings as chemoreceptors. These fibers travel in centrifugal bundles and have, contrary to Brettschneiders belief, connection with the perivascular nervous network. This type of ending is typical of centrifugal nerve fibers which end on blood vessels and represent one element of the double autonomic innervation of the blood vessels. Similar findings in the optic nerve were reported by Liss and Wolter (1956).

The various types of nervous endings with a definite relationship to the pituicytes are another proof of the great importance of these glial elements. 
The complex mechanism of storage and release of the neurosecretory substance, although under immediate control of hypothalamus, is carried out by the complicated nerve structures which are augmented by pituicytes. The pituicytes perform therefore much more specialized functions than any other type of glia. This fact is already evident from the morphology of the pituicytes (Liss, 1956).

Storage and release of the neurosecretory substances are the two functions of the different types of terminal nervous networks in the neurohypophysis. Some of these networks are completely independent from the pituicytes but others show intimate relationships with pituicytes either by surrounding them with a close network or by sending endings into the cells.

\section{Summary}

Different types of nervous terminations were described in the human neurohypophysis. The fibers of the hypothalamo-hypophysial tract terminate in the ventricular wall, on blood vessels and around pituicytes; they form terminal networks and end-glomeruli.

\section{Zusammenfassung}

Verschiedene Typen von Nervenendungen werden in der Neurohypophyse beschrieben. Die Fasern des Tractus hypothalamo-hypophyseus endigen in der Wand des Ventrikels, an Blutgefäßen und um Pituicyten. Sie bilden ein terminales Netzwerk und Endglomeruli.

\section{Résumé}

Les différents types des terminaisons nerveuses sont décrits dans la neurohypophyse humaine. Les fibres du tractus hypothalamo-hypophysaire se terminent dans la paroi ventriculaire, près de vaisseaux sanguins et dans les environs de pituicites. Elles forment des réseaux terminaux et des glomerules terminaux.

\section{References}

Bargmann, W., Das Zwischenhirn-Hypophysensystem. J. Springer, Berlin, 1954. 125 pp. - Bucy, P. C., The pars nervosa of the bovine hypophysis. J. Comp. Neurol., Philadelphia, 50 (1930), 505-520. - Buno, W., Sobre la estructura histologica de la Neurohipofisis. Arch. histol., B. Aires, 5 (1954), 195-226. - Brettschneider, H., Hypothalamus and Hypophyse des Pferdes. Morph. Jb., Leipzig, 96 (1955), 265-384. - Brettschneider, H., Ưber die Innervation der Spezialgefäße des Infundibulum. Zschr. mikrosk.-anat. Forsch., Leipzig, 62 (1956), 30-39. Liss, L., The cellular elements of the human neurohypophysis. J. Comp. Neurol., Philadelphia, 106 (1956), 501-525. - Liss, L., and J. R. Wolter, Zur Innervation der Blutgefäße des menschlichen Sehnerven. Klin. Mbl. Augenhk., Stuttgart, 129 (1956), 793-799. - Rennels, E. G., and G. A. Drager, The relationship of pituicytes to neurosecretion. Anat. Rec., Philadelphia, 122 (1955), 193-203. - Romeis, B., Der Hirnteil der Hypophyse. Quoted from Handbuch der mikr. Anat. Ed. W. von Moellendorff. J. Springer, Berlin. Vol. 6, Part 3 (1940), 389-474. Scharrer, E., and B. Scharrer, Neurosecretion. From Handbuch der mikr. Anat. Ed. W. von Moellendorff. J. Springer, Berlin. Vol. 6, Part 5 (1954), 953-1050. Spatz, H., Neues über Verknüpfung von Hypophyse und Hypothalamus. Acta neuroveget., Wien, 3 (1951), $1-49$.

Anschrift des Verfassers: Dr. L. Liss, Laboratory of Neuropathology, Neuropsychiatric Institute, University of Michigan Hospital, Ann Arbor, Michigan, USA. 